\title{
ASSOCIATION OF LIPID FRACTIONS LEVELS WITH CARDIOVASCULAR DISEASE
}

\author{
FERYAL H RADA*
}

Department of Pharmaceutical Chemistry, College of Pharmacy, Al-NahrainUniversity, Iraq. Email: fermsc33@yahoo.com

\author{
Received: 01 November 2016, Revised and Accepted: 07 December 2016
}

\begin{abstract}
Objective: The aim of this study is to analyze the association of serum lipids and lipoproteins in patients with angina pectoris.

Methods: A total of 110 patients (60 males and 50 females) with angina pectoris aged (55 \pm 5 ) years and 80 healthy controls (43 males and 37 females) aged (45 \pm 4 ) years were enrolled in this case-control study from the clinic of Al Yarmouk Hospital. Serum lipids, lipoprotein(a) [Lp(a)], apolipoprotein-A1, and apolipoprotein-B levels were measured and studied.
\end{abstract}

Results: The results of this study showed that increased odds of angina pectoris were associated with increased serum levels of Lp(a) more than serum levels of apolipoprotein-B.

Conclusions: Analysis of $\mathrm{Lp}(\mathrm{a})$ may be an important determinant of cardiovascular disease diagnosis.

Keywords: Lipoprotein(a), Apolipoprotein-A1, Apo lipoprotein-B, Angina pectoris.

(C) 2017 The Authors. Published by Innovare Academic Sciences Pvt Ltd. This is an open access article under the CC BY license (http://creativecommons. org/licenses/by/4. 0/) DOI: http://dx.doi.org/10.22159/ajpcr.2017.v10i3.15984

\section{INTRODUCTION}

Cardiovascular diseases are the most common cause of death worldwide. These facts advocated the researchers to modify the strategies used for prediction, prevention, and treatment of cardiovascular diseases.

Inflammatory mechanisms play an important role in the pathogenesis and prognosis of atherosclerosis. Many atherogenic lipoproteins imply a critical role in the proinflammatory reaction such as apolipoprotein $\mathrm{B}$, oxidized low-density lipoprotein (LDL), and lipoprotein(a) [Lp(a)]. Whereas antiatherogenic lipoproteins such as high-density lipoprotein and exert antiinflammatory function [1]

LDL cholesterol (LDL-C) is one of the most common predictors of cardiovascular diseases, but many studied suggested that apolipoprotein-B (apo-B) and non-high-density lipoprotein cholesterol (non-HDL-C) may be more precisely predict the risk of cardiovascular disease [2].

Apo-B is present as a single molecule in low-, intermediate-, and very LDL while apolipoprotein-A1 (apo-A1) is the major apolipoprotein associated with HDL. The ratio between the concentrations of apo-B and apo-A1 (apo-B/apo-A1) may reflect the balance between the opposing processes of arterial internalization of cholesterol and the reverse transport of cholesterol back to the liver $[3,4]$.

$\mathrm{Lp}(\mathrm{a})$ is composed of a LDL particle and a glycoprotein molecule known as apolipoprotein (a) [apo-(a)], which is structurally homologous to plasminogen (a) [5]. Therefore, $\operatorname{Lp}(\mathrm{a})$ has a tendency to exert both proatherogenic and prothrombotic effects(impaired fibrinolysis) in multiple stages of the atherosclerosis process, some of which are apo-(a) dependent other are related to the LDL component [6].

Lp(a) does not bind to the LDL - receptor, and accordingly, its level in circulation is not determined by the particle clearance but is determined by its synthesis $[7,8]$.

The goal of this case-control study was to measure the association (odds ratio [OR]) and the percent changes in relation to biochemical variables in patients with stable angina, focusing on serum levels of lipids, and lipoproteins.

\section{METHODS}

A total of 110 patients (60 males and 50 females), with stable angina pectoris aged (55 \pm 5$)$ years and 80 healthy controls (43 males and 37 females), aged $(45 \pm 4)$ years were recruited from the clinic of $\mathrm{Al}$ yarmouk hospital in Iraq. All participants evaluated through collecting medical histories and routine clinical laboratory tests. Exclusion criteria included patients with diabetes, liver disease, renal failure, and heart failure.

At fasting state, laboratory analyses of serum total cholesterol (TC), HDL-C, and triglycerides (TGs) levels measured using standard methods on automated analyzer.

In patients with TGs, $\leq 400 \mathrm{mg} / \mathrm{dl}$, LDL-C was calculating according to Friedewald's formula [9], while non-HDL-C was calculating by subtracting HDL-C from TC [10].

LDL-C $(\mathrm{mg} / \mathrm{dl})=\mathrm{TC}-[(\mathrm{TG} / 5)+\mathrm{HDL}-\mathrm{C}]$

Non-HDL-C $(\mathrm{mg} / \mathrm{dl})=$ TC - HDL-C

Lp (a), apo-A1, apo-B, and C-reactive protein (CRP) levels measured using enzyme-linked immunosorbent assay.

All eligible participants provided written informed consent to partake in this study. The study protocol conforms to the ethical guidelines and approved by the Institution's Ethics Committee.

All numerical data gave as mean \pm standard deviation with $95 \%$ confidence interval (CI). Comparisons of continuous variables were assessed by Student's $t$-test, $p$ values of $(0<0.05)$ were regarded to be statistically significant. All statistical analyses performed using Microsoft excel and SPSS version 18.0 for windows. 


\section{RESULTS}

The demographic and biochemical data of the studied participants stratified in Table 1.

Notably, the mean serum levels of lipids and lipoproteins that included TC, TG, LDL-C, non-HDL-C, apo-B and Lp(a) were considerably higher in patients with angina pectoris than in control subjects. Conversely, the mean serum levels of HDL-C and apo-A1 were substantially lower in cases as compared with control subjects (Table 1).

In Fig. 1, the plotted bar graph of the percent changes in lipid fractions and lipoproteins for patients with stable angina as related to healthy control showed high percent elevation in $\mathrm{Lp}(\mathrm{a})$ level and low percent elevation in apo-B level $(+133.88 \%,+9.32 \%)$, respectively. As well there was a high percent elevation noted in CRP level $(+167.5 \%)$ which is an inflammatory biomarker.

The association or correlation between the presence of angina and the increased levels of most interested lipids and lipoproteins more than normal levels were estimated using OR as shown in Table 2, in which high significant positive correlation was found between the selected variables and the presence of angina.

Moreover, the odds of increased level of $\operatorname{Lp}(\mathrm{a})$ was 2.2 times among cases than control $(\mathrm{OR}=2.2 ; 95 \% \mathrm{CI}=1.53-3.22, \mathrm{p}<0.001)$, while the odds of increased level of apo-B was 1.87 times among cases than control $(\mathrm{OR}=1.87$; 95\% $\mathrm{CI}=1.16-2.36, \mathrm{p}<0.001)$.

\section{DISCUSSION}

Low-density lipoprotein-cholesterol is a well-known risk factor for cardiovascular diseases, physicians in worldwide direct first-line of treatment toward lowering LDL-C.

Table 1: The demographic and clinical data of the studied participants

\begin{tabular}{lll}
\hline Variables & Control & Angina pectorispatients \\
\hline Number & 80 & 110 \\
Gender (male/female) & $43 / 37$ & $60 / 50$ \\
Age (year) & $45 \pm 4$ & $55 \pm 5$ \\
CRP (mg/L) & $1.54 \pm 1.03$ & $4.12 \pm 1.15^{* * *}$ \\
TC (mmol/L) & $3.77 \pm 0.525$ & $5.134 \pm 0.533^{* * *}$ \\
LDL-C (mmol/L) & $1.923 \pm 0.4$ & $2.912 \pm 0.527^{* * *}$ \\
HDL-C (mmol/L) & $1.258 \pm 0.272$ & $0.921 \pm 0.33^{* * *}$ \\
TG (mmol/L) & $1.538 \pm 0.21$ & $2.332 \pm 0.278^{* * *}$ \\
Non-HDL-C (mmol/L) & $2.469 \pm 0.321$ & $4.158 \pm 0.383^{* * *}$ \\
Apo- A1 (mg/dl) & $155.6 \pm 10.3$ & $143.7 \pm 15.5^{* * *}$ \\
Apo- B (mg/dl) & $96.4 \pm 12.6$ & $105.38 \pm 18.4^{* * *}$ \\
Lp(a) (mg/dl) & $12.28 \pm 4.8$ & $28.72 \pm 8.46^{* * *}$ \\
\hline
\end{tabular}

Data are presented as mean \pm SD (standard deviation) for continuous variables, ***High significant difference $\mathrm{p}<0.001$ versus control, $\mathrm{mg} / \mathrm{L}$ : Milligram per liter, mg/dl: Milligram per deciliter, mmol/L: Millimole per liter, Number: Sample size of the participants, CRP: C-reactive protein, TC: Total cholesterol, LDL-C: Low-density lipoprotein cholesterol, HDL-C: High-density lipoprotein cholesterol, Non-HDL-C: Non-high density lipoprotein cholesterol, TG: Triglyceride, Apo-A1: Apolipoprotein-A1, Apo-B: Apolipoprotein-B, Lp(a): Lipoprotein(a)

Table 2: Association between the presence of stable angina and the inceased levels of lipids and lipoprotein

\begin{tabular}{llll}
\hline Parameters & OR & $(\mathbf{9 5 \%} \mathbf{C I})$ & p value \\
\hline Apo-B & 1.87 & $(1.16-2.36)$ & $* * *$ \\
LDL-C & 2.05 & $(1.22-2.52)$ & $* * *$ \\
Non-HDL-C & 2.12 & $(1.4-2.87)$ & $* * *$ \\
Lp(a) & 2.2 & $(1.53-3.22)$ & $* * *$ \\
\hline
\end{tabular}

Sample size $(\mathrm{n})=80$ for control subjects, $(\mathrm{n})=110$ for angina pectoris patients, OR: Odds ratio, ${ }^{* * *}$ High significant correlation $\mathrm{p}<0.001, \mathrm{CI}$ : Confidence interval, Apo-B: Apolipoprotein-B, LDL-C: Low-density lipoprotein cholesterol, Non-HDL-C: Non-high density lipoprotein cholesterol, Lp(a): Lipoprotein(a)
This study denoted that increased serum levels of non-HDL-C, LDL-C, apo-B, and Lp(a) were comparably and consistently associated with increased odds of angina attack, but the odds of increased level of Lp(a) were more than the odds of increased level of apo-B; this may lead to suggest that the level of $\operatorname{Lp}(\mathrm{a})$ may be more useful for diagnosis and prognosis of angina than apo-B level.

As well high percent of increased level of Lp(a) among other lipids and lipoprotein in patients with stable angina may confirm the above suggestion.

There were many controversial opinions focuses on the superiority of the measurement of LDL-C, non-HDL, apo-bor Lp(a) that are consisted with the results of this study or contrasted.

First, LDL cholesterol calculated using Friedewald's formula that is accurate only when serum triglyceride levels lower than $400 \mathrm{mg} / \mathrm{dl}$, so this equation is particularly inaccurate once the patients have triglycerides levels higher than $400 \mathrm{mg} / \mathrm{dl}$ or have type III hyperlipoproteinemia [11]

Second, non-HDL-C calculated to provide an estimate of cholesterol levels in the atherogenic particles including low-, intermediate-, and very LDL. Arsenault et al., in 2009, suggested that non-HDL-C was associated with coronary heart disease risk independent of their plasma LDL-C levels [12]

Moreover, the National Cholesterol Education Program Adult Treatment Panel III guideline in 2001 mentioned that non-HDL-C is not a novel concept and recommended as a secondary target for patients with triglycerides levels $>200 \mathrm{mg} /$ dl, i.e., non-HDL-C is useful for estimating LDL-C atherogenicity in patients with triglycerides levels outside of Friedewald's formula's range [13].

Third, the measurement of apo-B level in some study suggests being superior to non-HDL-C level and should be introduced into routine care [14], while others do not support routine measurement of apo-B [15].

Likewise, the Joint European Society of Cardiology/European Atherosclerosis Society guidelines on the management of dyslipidemias recommended the measurement of apo-B as a better index of adequacy of LDL-lowering therapy than measurement of LDL-C. If the measurements of apo-B are not available, the guidelines consider the use of non-HDL-C [16].

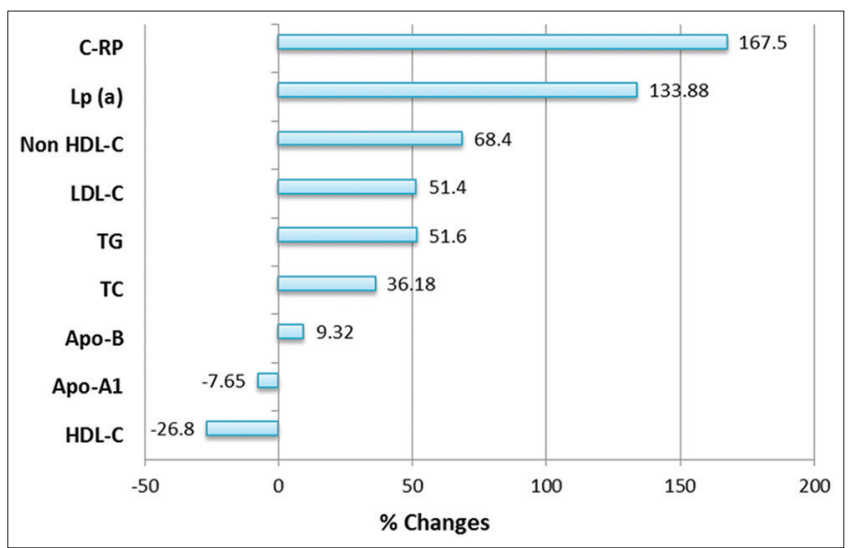

Fig. 1: Percent changes in lipids, lipoproteins, and C-reactive protein for patients with angina pectoris as compared with control subjects. Sample size $(n)=80$ for control subjects, $(n)=110$ for angina pectoris patients, HDL-C: High-density lipoprotein cholesterol, Non-HDL-C: Non-high density lipoprotein cholesterol, Apo-A1: Apolipoprotein-A1, Apo-B: Apolipoprotein-B, TC: Total cholesterol, TG : Triglyceride, LDL-C: Low density lipoprotein cholesterol, Lp(a): Lipoprotein(a), CRP: C-reactive protein 
Fourth, the elevated level of $\operatorname{Lp}(\mathrm{a})$ was strongly correlated with the degree of coronary atherosclerosis as suggested by Batalla et al. [17] and with the restenosis after revascularization as mentioned by Miyata et al. [18]. However, Skinner et al. not confirmed the prognostic value of $\mathrm{Lp}(\mathrm{a})$ levels in patients with coronary artery disease [19].

Moreover, the guidance's of treatment toward lowering $\operatorname{Lp(a)}$ in patients with cardiovascular diseases may be controversial; some study revealed that the reduction of $\mathrm{Lp}(\mathrm{a})$ level using niacin treatment lack its efficacy for lowering vascular risk [20]. Another study mentioned the safety of lowering Lp(a) levels in patients with coronary heart disease using acetrapib, a cholesterol ester transfer protein inhibitor [21].

Another drug like statin [22] or plant like blend of Moringa oleifera could be using for lowering blood levels of cholesterol and triglyceride either by inhibiting the de novo synthesis or by inhibiting the intestinal absorption of cholesterol [23].

\section{CONCLUSION}

Among lipids and lipoproteins variables, although Non-HDL-C and LDL-C measurements provide a convenient, valuable, and clinically plausible end point but the measurement of $\operatorname{Lp}(\mathrm{a})$ is more accurate than others for the diagnosis and prognosis of atherosclerosis-related diseases.

\section{ACKNOWLEDGMENTS}

I would like to thank the Department of Cardiology and Internal Medicine for assistance with data collection.

\section{REFERENCES}

1. Malaguarnera M, Vacante $\mathrm{M}$, Avitabile $\mathrm{T}$, Malaguarnera $\mathrm{M}$, Cammalleri L, Motta M. L-Carnitine supplementation reduces oxidized LDL cholesterol in patients with diabetes. Am J Clin Nutr 2009;89(1):71-6.

2. Emerging Risk Factors Collaboration, Di Angelantonio E, Sarwar N, Perry P, Kaptoge S, Ray KK, et al. Major lipids, apolipoproteins, and risk of vascular disease. JAMA 2009;302(18):1993-2000.

3. Walldius G, Jungner I. Apolipoprotein B and apolipoprotein A-I: Risk indicators of coronary heart disease and targets for lipid-modifying therapy. J Intern Med 2004;255(2):188-205.

4. Walldius G, Jungner I. Rationale for using apolipoprotein B and apolipoprotein A-I as indicators of cardiac risk and as targets for lipidlowering therapy. Eur Heart J 2005;26:210-2.

5. Marcovina SM, Koschinsky ML. Lipoprotein(a) as a risk factor for coronary artery disease. Am J Cardiol 1998;82(12A):57U-66.

6. Hervio L, Chapman MJ, Thillet J, Loyau S, Anglés-Cano E. Does apolipoprotein(a) heterogeneity influence lipoprotein(a) effects on fibrinolysis? Blood 1993;82:392-7.

7. Berglund L, Ramakrishnan R. Lipoprotein(a): An elusive cardiovascular risk factor. Arterioscler Thromb Vasc Biol 2004;24(12):2219-26.

8. Boffa MB, Marcovina SM, Koschinsky ML. Lipoprotein(a) as a risk factor for atherosclerosis and thrombosis: Mechanistic insights from animal models. Clin Biochem 2004;37(5):333-43
9. Friedewald WT, Levy RI, Fredrickson DS. Estimation of the concentration of low-density lipoprotein cholesterol in plasma, without use of the preparative ultracentrifuge. Clin Chem 1972;18(6):499-502.

10. Cui Y, Blumenthal RS, Flaws JA, Whiteman MK, Langenberg P, Bachorik PS, et al. Non-high-density lipoprotein cholesterol level as a predictor of cardiovascular disease mortality. Arch Intern Med 2001;161:1413-9.

11. Nauck M, Warnick GR, Rifai N. Methods for measurement of LDL-cholesterol: A critical assessment of direct measurement by homogeneous assays versus calculation. Clin Chem 2002;48(2):236-54.

12. Arsenault BJ, Rana JS, Stroes ES, Després JP, Shah PK, Kastelein JJ, et al. Beyond low-density lipoprotein cholesterol: Respective contributions of non-high-density lipoprotein cholesterol levels, triglycerides, and the total cholesterol/high-density lipoprotein cholesterol ratio to coronary heart disease risk in apparently healthy men and women. J Am Coll Cardiol 2009;55:35-41.

13. Grundy SM, Cleeman JI, Merz CN, Brewer HB Jr, Clark LT, Hunninghake DB, et al. Implications of recent clinical trials for the National Cholesterol Education Program Adult Treatment Panel III guidelines. Circulation 2004;110:227-39.

14. Sniderman AD, Williams K, Contois JH, Monroe HM, Mc Queen MJ, de Graaf J. A meta-analysis of low-density lipoprotein cholesterol, nonhigh-density lipoprotein cholesterol, and apolipoprotein B as markers of cardiovascular risk. Circ Cardiovasc Qual Outcomes 2011;337:4-45.

15. Lavie CJ, Milani RV, O’Keefe JH. To B or not to B: Is non-high-density lipoprotein cholesterol an adequate surrogate for apolipoprotein B? Mayo Clin Proc 2010;85:446-50.

16. European Association for Cardiovascular Prevention \& Rehabilitation, Reiner Z, Catapano AL, De Backer G, Graham I, Taskinen MR, et al. ESC/EAS Guidelines for the management of dyslipidaemias: The task force for the management of dyslipidaemias of the European Society of Cardiology (ESC) and the European Atherosclerosis Society (EAS). Eur Heart J 2011;32:1769-818.

17. Batalla A, Reguero JR, Cubero GI. Plasma lipoprotein(a) and severity of angiographic coronary artery disease. J Am Coll Cardiol 1999;33:590-1.

18. Miyata M, Biro S, Arima S, Hamasaki S, Kaieda H, Nakao S, et al. High serum concentration of lipoprotein(a) is a risk factor for restenosis after percutaneous transluminal coronary angioplasty in Japanese patients with single-vessel disease. Am Heart J 1996;132:269-73.

19. Skinner JS, Farrer M, Albers CJ, Piper K, Neil HA, Adams PC. Serum $\mathrm{Lp}$ (a) lipoprotein concentration is not associated with clinical and angiographic outcome five years after coronary artery bypass graft surgery. Heart 1997;78:131-5.

20. HPS-THRIVE Collaborative Group. HPS2-THRIVE randomized placebo-controlled trial in 25673 high-risk patients of ER niacin/ laropiprant: Trial design, pre-specified muscle and liver outcomes, and reasons for stopping study treatment. Eur Heart J 2013;34(17):1279-91.

21. Cannon CP, Shah S, Dansky HM, Davidson M, Brinton EA, Gotto AM, et al. Safety of anacetrapib in patients with or at high risk for coronary heart disease. N Engl J Med 2010;363(25):2406-15.

22. Mmr MM, Tripathy M, Majeed A. The prospect, promises and hindrances of statin base molecules: Look back to look forward. Int J Pharm Pharm Sci 2016;8:22-33.

23. Gururaja GM, Mundkinajeddu D, Kumar AS, Allanj J, Dethe SM, Agarwal A. Cholesterol lowering potentials of a blend of standardized methanol extracts of Moringa oleifera leaves and fruits in albino wistar rats. Int J Pharm Pharm Sci 2016;8:262-8. 